\title{
Characteristics of Spherical Organic Particles Emitted from Fixed-Bed Residential Coal Combustion
}

\author{
Tafadzwa Makonese ${ }^{1, *}$, Johan Meyer ${ }^{2}$ and Sune von Solms ${ }^{2}$ \\ 1 Faculty of Engineering and the Built Environment, University of Johannesburg, P. Bag 524, Auckland Park, \\ Johannesburg 2006, South Africa \\ 2 School of Electrical and Electronic Engineering Sciences, Faculty of Engineering \& the Built Environment, \\ University of Johannesburg, P. Bag 524, Auckland Park, Johannesburg 2006, South Africa \\ * Correspondence: tmakonese@uj.ac.za; Tel.: +27-11-559-6988
}

Received: 21 May 2019; Accepted: 18 July 2019; Published: 1 August 2019

check for updates

\begin{abstract}
Residential coal combustion is one of the most significant sources of carbonaceous aerosols in the Highveld region of South Africa, significantly affecting the local and regional climate. This study investigated single coal-burning particles emitted when using different fire-ignition techniques (top-lit up-draft versus bottom-lit up-draft) and air ventilation rates (defined by the number of air holes above and below the fire grate) in selected informal braziers. Aerosol samples were collected on nucleopore filters at the Sustainable Energy Technology and Research Centre Laboratory, University of Johannesburg. The individual particles ( 700) were investigated using a scanning electron microscope equipped with energy-dispersive X-ray spectroscopy (EDX). Two distinct forms of spherical organic particles (SOPs) were identified, one less oxidized than the other. The particles were further classified into electronically dark and bright. The EDX analysis showed that $70 \%$ of the dark spherical organic particles had higher $(\sim 60 \%)$ relative oxygen content than in the bright SOPs. The morphology of spherical organic particles were quantified and classified into four categories: $\sim 50 \%$ were bare single particles; $35 \%$ particles were aggregated and formed diffusion accretion chains; $10 \%$ had inclusions, and $5 \%$ were deformed due to impaction on filter material during sampling. This study concludes that there are two distinct kinds of coal burning spherical organic particles and that dark SOPs are less volatile than bright SOPs. The authors also show that these spherical organic particles are similar in nature and characteristics to tar balls observed in biomass combustion and that they have the potential to absorb sunlight thereby affecting the earth's radiative budget and climate. This study provides insights into the mixing states, morphology, and possible formation mechanisms of these organic particles from residential coal combustion in informal stoves.
\end{abstract}

Keywords: aerosols; carbonaceous spherical particles; coal braziers; morphology; stoves

\section{Introduction}

Aerosol particles are ubiquitous in the troposphere and due to their shapes and sizes, can influence the global climate and the environment [1]. Aerosol particles affect the climate by acting as cloud condensation nuclei, scattering light, and by transmission and absorption of radiation. The magnitude of the radiative effects of aerosol particles depend on the following properties: Composition, size and size distribution, abundance, hygroscopic properties, surface properties, aerosol density, and refractive indices [1]. The traditional methods of studying the physicochemical properties of aerosol particles is through bulk methods. This enables large numbers of particles to be analyzed en masse [1]. However, the resultant data does not provide information about individual aerosol species and mixing states. There is a need to study individual particles using electron microscope techniques to enhance our understanding of how particles transform during atmospheric transport [2]. 
Microscopy techniques have become the most sought after and useful tools in coal combustion and atmospheric research, particularly, the use of beam microscopes which include scanning and transmission microscopes [3-5]. Microscopy techniques can be useful in the study of a range of particle properties since important information on particles resides in the morphology and chemical composition of individual particles [6,7]. The high-resolution scanning electron microscope (HRSEM) has been used to a lesser extent in coal combustion research [8-10]. In published and peer-reviewed literature, there is limited information regarding characterizing emissions from residential coal combustion processes using an ultra-high resolution field emission gun scanning electron microscope, except for the work of Wentzel et al. [11] who characterized aerosols from the Soweto atmosphere, and Gwaze [6] who characterized aerosols from coal combustion. Unfortunately, their work has not been followed up. However, it is vital to understand the modes of formation and transformation of conglomerates originating from low-temperature coal combustion. This study proposes the use of a high-resolution SEM for characterizing and assessing the morphology and characteristics of coarse $(>10 \mu \mathrm{m})$ and fine particles $(<2.5 \mu \mathrm{m})$.

The severity of the impact of particulate matter (PM) on human health and the environment is determined by chemical and physical properties of the PM $[12,13]$. The physical properties include the size and morphology, while chemical characterization regarding organic and elemental composition is significant in assessing the overall impact of the particulate matter [12,14]. During the combustion of fuels such as coal, primary particles aggregate to form clusters, with some clusters over $100 \mu \mathrm{m}$ in length [11]. These agglomerates have morphologies that can be measured using electron microscopy techniques $[15,16]$. For example, fractal dimensions of particles including other shape descriptors such as aspect ratio, the roundness of particles and the root form factor have been used to characterize the morphological properties of agglomerates, instead of using conventional optical (light scattering and absorption) methods $[12,15,17]$.

This paper presents the first comprehensive and systematic study of spherical organic particles (SOPs) emissions from informal packed-bed coal stoves in use in South Africa, using a scanning electron microscope (SEM) equipped with energy dispersive spectroscopy (EDX). This study is limited to spherical organic particles emitted from typical fixed-bed coal-burning braziers used in the South African townships.

\section{Experiments}

\subsection{Experimental Fuels and Stoves}

Smoke particles were collected from coal fires set in a high and low air ventilated coal-burning braziers purchased from users in an informal settlement of Setswetla in Alexandra Township, Johannesburg, South Africa. The combustion experiments were conducted under laboratory conditions at the Sustainable Energy Technology and Research (SeTAR) Centre laboratory at the University of Johannesburg. The stoves were hand-made out of round 20-L metal drums with perforations of varying sizes around the sides, and a wire grate across the middle of the containers to support the coal. A detailed description of the experimental stoves has been presented elsewhere [18].

In these experiments, D-grade type coal from Slater Coal mine in Mpumalanga, South Africa was used as it is commonly used in the Townships in the Gauteng province for cooking and space heating during the winter months. The experimental fuels were evaluated for proximate and ultimate determination appropriate standard methods at an independent laboratory. Sufficient batches of coal were purchased to conduct a range of comparative tests and were further characterized for thermal content, elemental (proximate) analysis, moisture and ash content at Bureau Veritas (Paris, France) Testing and SGS South Africa (Pty) Ltd. (Woodmead, South Africa). The coal had a calorific value of $23.4 \mathrm{MJ} / \mathrm{kg}$ and an ash content of $24.2 \%$. The full results of the proximate and ultimate determination of the D-grade coal have been presented elsewhere [19]. 


\subsection{Fire-Ignition Techniques for Electron Microscope Samples}

Since domestic coal combustion is usually initiated with some kindling (e.g., wood, paper or kerosene), there is a need to separate coal combustion emissions from emissions due to the combustion of the kindling. When two fuels are burned together, it is a challenge to separate the emissions from each fuel [20]. A suggested approach is to start combustion with the kindling, which is typically used for igniting the coal since the total emission from both fuels can be attributed to the use of the coal in real-world scenarios. However, this approach has the potential to overestimate total emissions, especially in situations where emission factors are applied to fuel use databases where coal consumption and wood consumption are reported separately [20]. Furthermore, the measurement would not be representative of continuously burning fires used for heating or prolonged (commercial) cooking purposes with intermittent refueling [20].

An alternative method, the one used in this study was first used by Bond et al. [20] and entailed starting the combustion using a clean-burning, low-smoke fuel. The authors in that study reported the use of Kingsford ${ }^{\circledR}$ barbeque briquettes, which have low particulate emissions during combustion. It was assumed that the emissions from the barbecue briquettes would cease before the first coal was burned. Wood kindling, on the other hand, showed high emissions that persisted into subsequent coal cycles. In our preliminary experiments, it was found that pinewood had high particulate emissions at the start of ignition, but the emissions did not persist into subsequent coal cycles. Pinewood as a kindling was faster at igniting the coal compared to locally available barbeque compressed briquettes. Pinewood was therefore used to initiate combustion so that the coal emissions could be isolated. Thus, the particle morphologies presented herein are representative of coal combustion smoke without being influenced by the kindling. However, to determine the total particulate matter attributable to coal combustion (e.g., to assess health effects or net effect of fuel switching), kindling emissions require consideration [20].

For electron microscope sampling using the top-lit updraft (TLUD) method, a unique ignition strategy was needed to obtain kindling-free emissions: A test brazier was prepared with $2000 \mathrm{~g}$ of coal placed directly on the grate. In a second, similar brazier, $1000 \mathrm{~g}$ of coal was ignited using $150 \mathrm{~g}$ of pine wood and $20 \mathrm{~g}$ paper used as kindling. After ignition, the coal was allowed to coke until red-hot. After that, the hot char was transferred to the test brazier and placed on top of the previously loaded $2000 \mathrm{~g}$ of coal. As soon as the red-hot embers had been transferred to the test brazier, particulate sampling commenced.

For the bottom-lit downdraft (BLUD) also referred to as the traditional fire ignition method, $1000 \mathrm{~g}$ of coal was added to a coal brazier with similar configurations as the test brazier. The same amount of kindling as in the TLUD method was added and the fire started until the coals turned red-hot. The red embers were then transferred to the test braziers onto the grate. After that, $2000 \mathrm{~g}$ of raw coal was added on top of the burning red coal embers. This marked the onset of particulate sampling for microscopy examination.

\subsection{Separation of Ignition Phases}

The dynamics of particle morphology formation and development during packed-bed coal combustion can be explained using fuel-bed temperature and emission profiles for the different fire-ignition methods. The ignition phases were separated based on the technique developed by Makonese et al. [18]. The temperature and carbon monoxide emission profiles from the combustion of coal in a typical brazier were monitored using $5 \mathrm{~mm}$ K-type thermocouples and the Testo XL 350 flue gas analyzer, respectively. The behavior of the temperature and $\mathrm{CO}$ emission curves was explained by reference to the photographs of braziers ignited using the top-lit updraft (TLUD) and the bottom-lit updraft (BLUD) methods. The ignition phase (first $10 \mathrm{~min}$ of combustion) was characterized by dense white to brown smoke, with high readings of $\mathrm{CO}$ emissions (4500 ppm) and low temperature $\left(<200^{\circ} \mathrm{C}\right)$. During the flaming stage (which lasted for $90 \mathrm{~min}$ after the ignition phase when using the TLUD method), the temperature increased to above $400{ }^{\circ} \mathrm{C}$, while the CO emissions decreased ( 1500 ppm) 
and there was a significant flame protruding from the top of the stove. During the char-burning phase (which lasted for $80 \mathrm{~min}$ after the flaming period in the TLUD lit brazier), the CO emissions dropped to $\sim 900 \mathrm{ppm}$, and the fuel bed temperature remained stable at $\sim 300{ }^{\circ} \mathrm{C}$. This phase resulted in no visible flames or smoke emissions and was characterized by red-hot embers. A full description of the separation of the combustion phases in coal-burning braziers is presented in Makonese et al. [18].

\subsection{Experimental Setup}

To investigate the effect of ageing (on the scale of a few seconds) on smoke emissions, and to note how commonly these conglomerates and spherical organic particles occur in different fires and ventilation rates, aerosols contained in coal smoke-laden exhaust were collected $\sim 5 \mathrm{~m}$ above the brim of the burning brazier through a $4 \mathrm{~m}$ long exhaust duct (Figure 1).

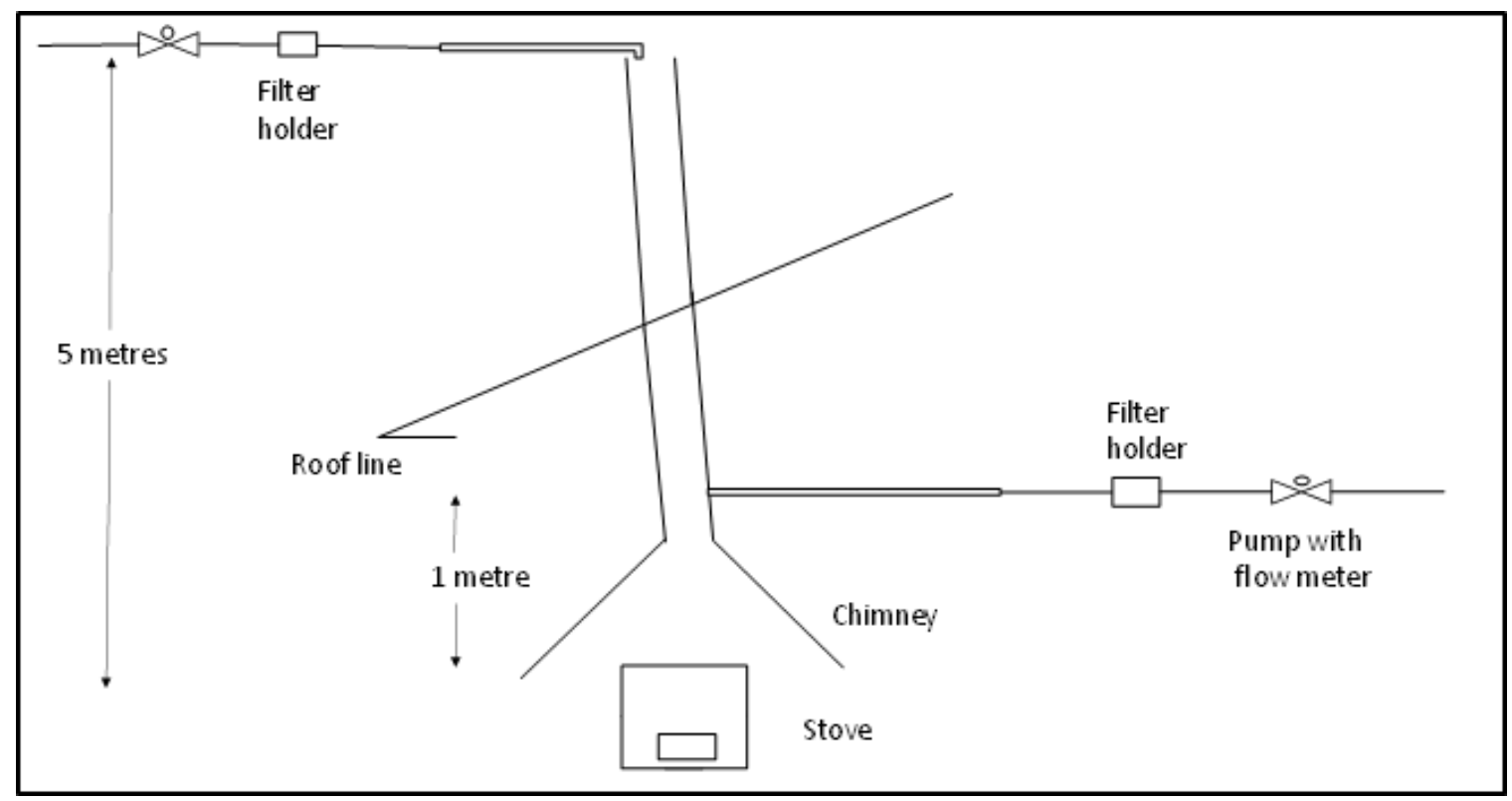

Figure 1. A schematic of the experimental set up. Not drawn to scale.

The sampling configuration for smoke particles included, in sequence, a stainless-steel channel, a filter holder with nucleopore membrane filters $(37 \mathrm{~mm})$, and a Gast pump with a calibrated flow meter. The flow rate was kept constant at $5 \mathrm{~L} / \mathrm{min}$, and the sampling was done for $10 \mathrm{~s}$ to avoid clogging the filter membrane with excess smoke particles.

\subsection{Electron Microscopy and Sample Preparation}

Electron microscopy techniques are widely used to image the shape and structure (i.e., morphology) of solid surfaces or particles. By using the reflection (scattering) of electrons instead of light, as in conventional microscopy, the resolution in the nanometer scale can be obtained. In the present work, the JSM 5800LV SEM at the University of Pretoria and the Tescan Vega3 LM at the University of Johannesburg were used to observe particle morphologies from coal-burning fires. Both instruments were equipped with energy dispersive spectroscopy (EDX), which provides the possibility to analyze the chemical compositions of PM. The Tescan Vega3 LM used for the semi-quantitative analysis of the SOP in this study was equipped with the X-Max silicon drift detector EDX from Oxford Instruments. The samples from real-world uses of braziers were collected on quartz fiber filters. Samples from laboratory tests were collected on polycarbonate membrane filters using suction pumps.

The three most common modes of operation in SEM analysis are: (i) Backscattered electron imaging (BSE); (ii) secondary electron imaging (SEI); and (iii) electron dispersive spectroscopy (EDX). The SEM is not without its limitations. There is evidence that suggests that the samples under 
observation in SEM are susceptible to mass loss of adsorbed water or volatiles due to the necessity of operating in a vacuum and possible damage by electron beam heating or electrostatic disruption [6]. Therefore, only non-volatile particle components can be characterized during the SEM analyses [17]. The influence of the accelerating voltage of the electron beam on the shape on the aerosol particles was characterized by varying the accelerating voltages between 10 and $20 \mathrm{kV}$. Within this voltage range, there was found to be little or no change in the shape of the aggregates. In this study, a nominal accelerating voltage of $20 \mathrm{kV}$ was used for most images. Compared to lower accelerating voltages (e.g., $10 \mathrm{kV}$ ), the use of $20 \mathrm{kV}$ improves imaging of the surface and internal structure of the particles [17].

In addition to particle damage when using the SEM, there is a lack of 3D information, which may lead to biases in sizing measurements of particles deposited on the filter material. Gwaze [6] suggested that it is possible to tilt the sample support and measure particle sizes in several electron beam projections, which can then be computed to particle volumes. However, the procedure is rather complicated, difficult and tedious. As such, this procedure was not adopted in this study.

Analytical elemental measurements were performed evaluating the X-rays emitted during electron bombardment on particles to determine elements with an atomic number higher than five using EDX. According to Goldstein et al. [21], the interaction volume of the sample with the energy beam is a function of the atomic number of the sample and the electron beam energy. For accelerating voltages of 15 and $20 \mathrm{kV}$ used in this study, the interaction volume could be of the order of a few micrometers for low atomic number samples, thus negatively biasing bulk analyses of Aitken and accumulation mode size particles [6]. The EDX analyses in this study were therefore useful for deriving the elemental composition of coarse mode particles.

Polycarbonate membrane filters with sample particles were cut and tapped onto a double-sided carbon tape mounted on an SEM stub. This mount enables the analyst to determine the particle morphology, outer surface structure and the external elemental distribution of individual aerosol particles. The filters were coated before sampling, as in the Gwaze [6] study, with a thin layer of gold $(<10 \mathrm{~nm})$ using an Emitech Sputter Coater to enhance contrast in SEM images and minimize electrostatic charging of particles. Some samples were analyzed uncoated, and it was discovered that particles could jump off the filter or restructure due to charging, especially at high magnifications. High magnifications were essential in this study because primary particles could be as small as $20 \mathrm{~nm}$ in diameter [6].

The elemental composition and morphology were noted for each particle and compiled for each sample. As in the Kutchko and Kim [22] study, the elemental analysis was performed in a spot mode, in which the beam is localized on a single area manually chosen within the field of view. The EDX is not a quantitative measure of elemental concentration although Kutchko \& Kim [22] opined that relative amounts could be inferred from relative peak heights.

The filters were analyzed shortly after sampling and on subsequent days. Throughout the days, there were no noticeable changes in the morphology of the particles. The aggregates were selected by changing the field of view and following random trajectories on the filter. All particles analyzed in the field of view were photographed to avoid operator bias. The magnification was chosen to allocate an individual particle or aggregate to the whole scan area. The output images were acquired with $1024 \times 768$ pixels and 256 grey scale levels [6].

\subsection{Quality Assurance}

The calibration of the SEM was done similarly to what is reported in Gwaze [6]. The calibration of the instrument was verified by measuring standard grids of alternating $\mathrm{SiO}_{2} / \mathrm{Si}$ surfaces with lateral (XY) dimensions between 0.9 and $15 \mu \mathrm{m}$, and polystyrene latex (PSL) spheres of diameters of $0.126 \pm 0.001 \mu \mathrm{m}$ and $0.600 \pm 0.005 \mu \mathrm{m}$. The deviations between measured sizes of both the standard grids and PSL spheres and nominal specifications were below 7\%. The X-ray detector was calibrated regularly with $\mathrm{Cu}$ standard sample. 


\section{Results and Discussion}

The study of particle morphology is essential because it provides knowledge of the size and shape, and possible composition of primary particles emitted from combustion processes. The information on the course and fine particle morphology in fixed-bed domestic coal combustion devices is scarce. In this section, detailed results are presented on particle morphology during different combustion conditions from a suite of coal-burning braziers. Semi-quantitative energy dispersive $\mathrm{X}$-ray spectrometry results are presented to demonstrate elemental compositions associated with the different morphologies.

\subsection{Identification of Spherical Organic Particles}

Figure 2 shows a micrograph of spherical organic particles sampled and fractal aggregates (collected $<1 \mathrm{~m}$ from the brazier) from a BLUD fire during late pyrolysis. The size and shape of the spherules were dependent on the ventilation rates. In the high ventilation brazier, fewer spherical particles were observed compared to samples collected from the low ventilation brazier. Carbon and oxygen comprised the bulk of the elemental composition of these spherules. Pósfai et al. [23] argued that particles of this type are carbonaceous and are formed in smoldering fires and their abundance increases in the atmosphere with the age of the plume. The observed particles are like spherical C-rich particles collected from coal combustion processes in previous studies [24]. As a result, this study has termed these particles, spherical organic particles. However, since EDX analyses only gave elemental compositions, there was no direct evidence that the C-element in these particles occurred in organic compounds.

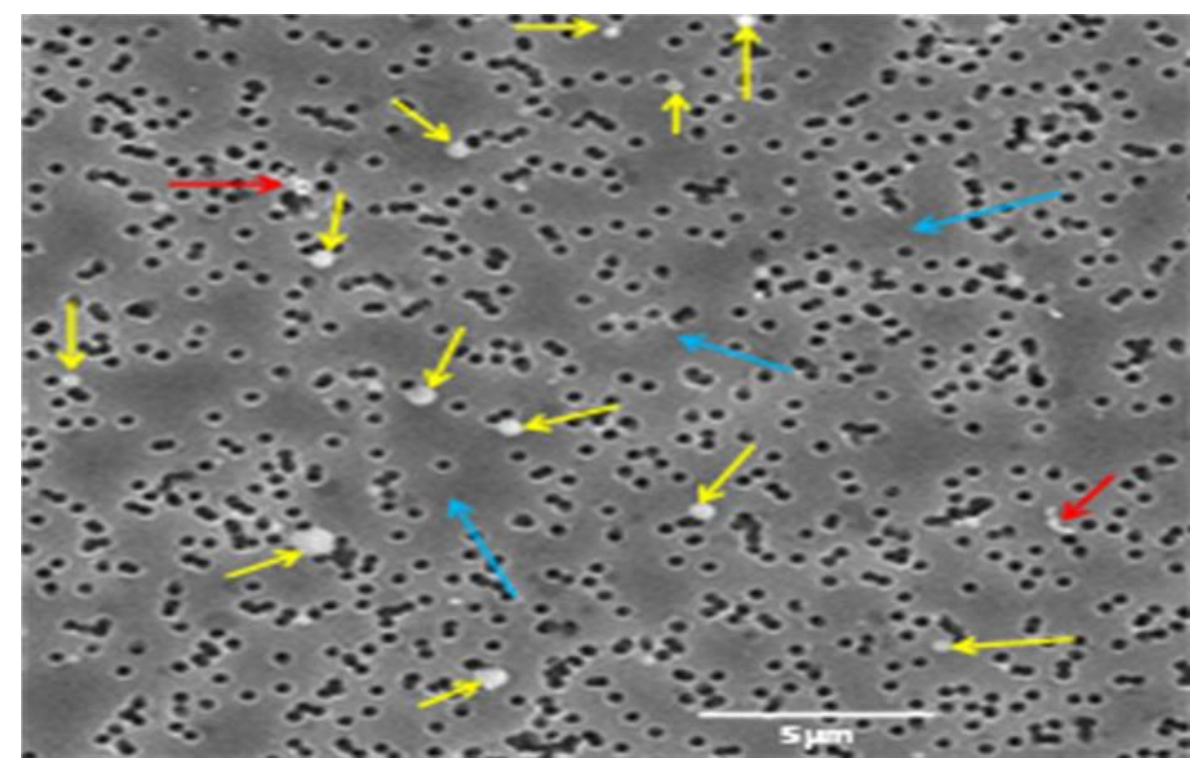

Figure 2. SEM image showing particles emitted from bottom-lit downdraft (BLUD) low ventilation fire with the advent of visible flames (late pyrolysis). The yellow arrows show spherical organic particles; the red arrows show fine mode soot particles and the blue arrows show dark halos indicating the presence of moisture in the sample.

Spherical organic particles have similar morphologies to fly ash, though they are smaller, usually below $2 \mu \mathrm{m}$ in diameter, while fly ash could be more than $5 \mu \mathrm{m}$ in diameter. Without chemical information from each particle, it is impossible in this study to identify these particles distinctively apart due to the overlap in size and similarity in morphology. Unlike organic coated particles and sulphate spherules, the observed spherical organic particles were not beam sensitive and did not evaporate under prolonged exposure to the electron beam at an $\mathrm{HV}$ of 20 . This result is similar to findings of tar-balls reported from biomass combustion $[16,25,26]$. Fu et al. [27] argued that such insusceptibility 
against the electron beam might be because of the presence of high-molecule organic compounds, such as HULIS (i.e., humic-like substances that are typically polycyclic aromatic hydrocarbons).

\subsection{Ageing of Condensed Matter Particles}

The results are presented for the BLUD and TLUD ignition methods in both the high and low ventilation braziers, during the early and late pyrolization phases and the char formation phase of the fire.

\subsubsection{During the Pyrolization Phases}

The results show when sampling particles $\sim 5 \mathrm{~m}$ above the combustion devices, spherical organic particles (SOPs) are dominant for both fire-ignition methods. TLUD fires emitted spherical organic particles with smaller mode diameter compared to BLUD fires. The spherical particles form diffusion accretion chains in TLUD fires, whereas BLUD fires show numerous condensation spherules as shown in Figure 3. This suggests the particle mass concentration and particle mean diameters are influenced by the ignition method employed, and the subsequent evolution of particles and gases through and above the fuel bed.
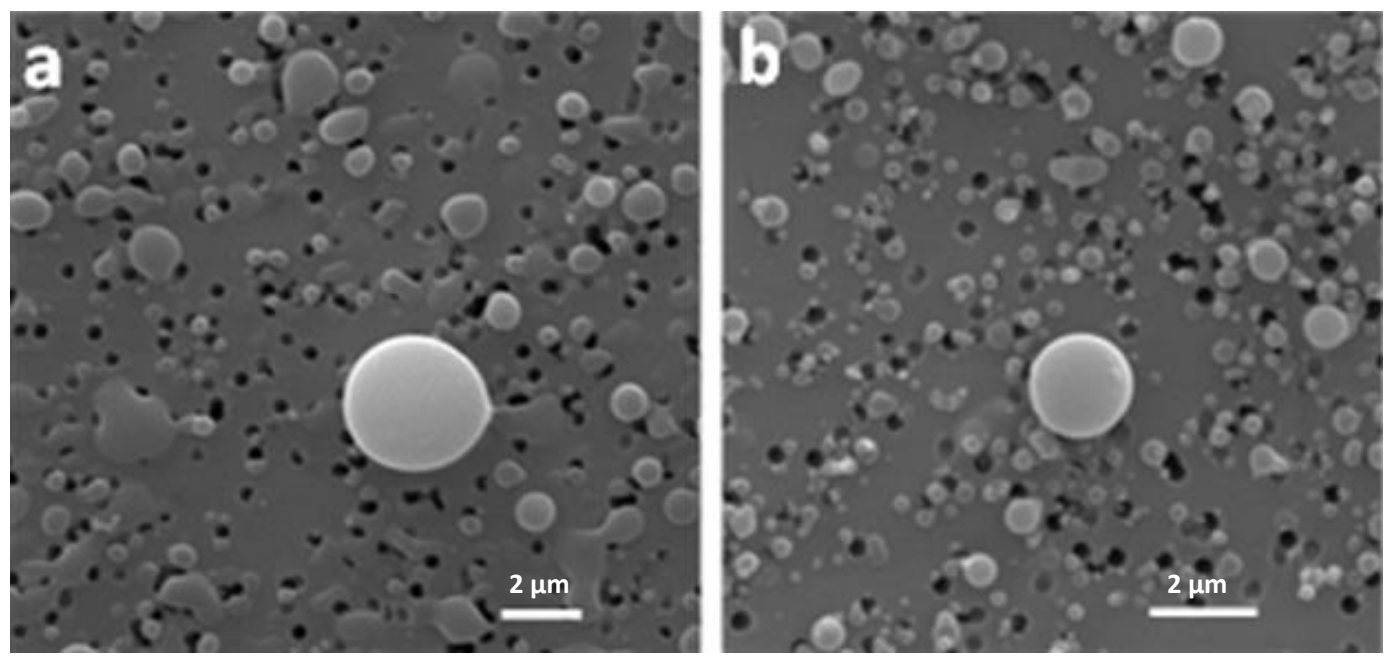

Figure 3. Spherical particles sampled during early pyrolysis from BLUD fires in (a) a low ventilation brazier, and (b) a high ventilation brazier.

Figure 3 shows micrographs of condensed matter particles sampled during the early pyrolization phase from BLUD fires in low and high ventilation braziers, respectively. For the low ventilation rates, the spherical organic particles observed were two to three times larger compared to those observed for the high ventilation rate. Further, the presence of a thick film of carbonaceous material on samples collected from the low ventilation brazier was noted (Figure 3a).

Figure 4 shows an electron micrograph of a typical giant spherical organic particle collected from the low ventilation BLUD during the coal pyrolization. These particles are three-fold larger compared to particles from the corresponding high ventilation BLUD brazier. This suggests that ventilation rates may influence the particle mode diameter of the spherical particles in BLUD fires. However, it should be noted that this is a qualitative observation based on visual inspection of the micrographs-automated particle recognition, and counting facilities were not available on the SEM instrument used. There is a need in future studies to use commercial particle sizers (e.g., differential mobility particle sizers (DMPS) and scanning mobility particle sizer (SMPS) to analyze the specific mode diameter of particles obtained from such studies. In the absence of these expensive tools, it is suggested to use the ImageJ software package (free-online graphics software) for image processing and 
analysis. However, this requires high-level expert knowledge on how to threshold the SEM images before analyzing the particles.

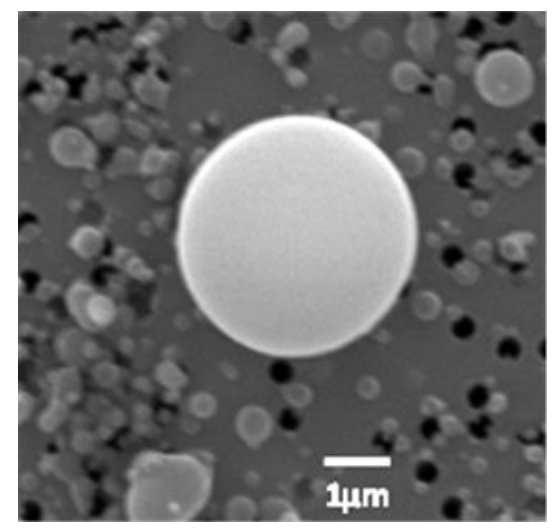

Figure 4. Giant spherical organic particles from the ignition phase of a BLUD fire.

For the TLUD method, diffusion accretion chains were observed during the pyrolization phase (with the fire not completely established above the coal bed) in both the low ventilation and the high ventilation braziers. The size and length of the diffusion accretion chains were dependent on the ventilation rates. Low ventilation TLUD produced long diffusion accretion chains compared to the high ventilation emissions as shown in Figure 5.
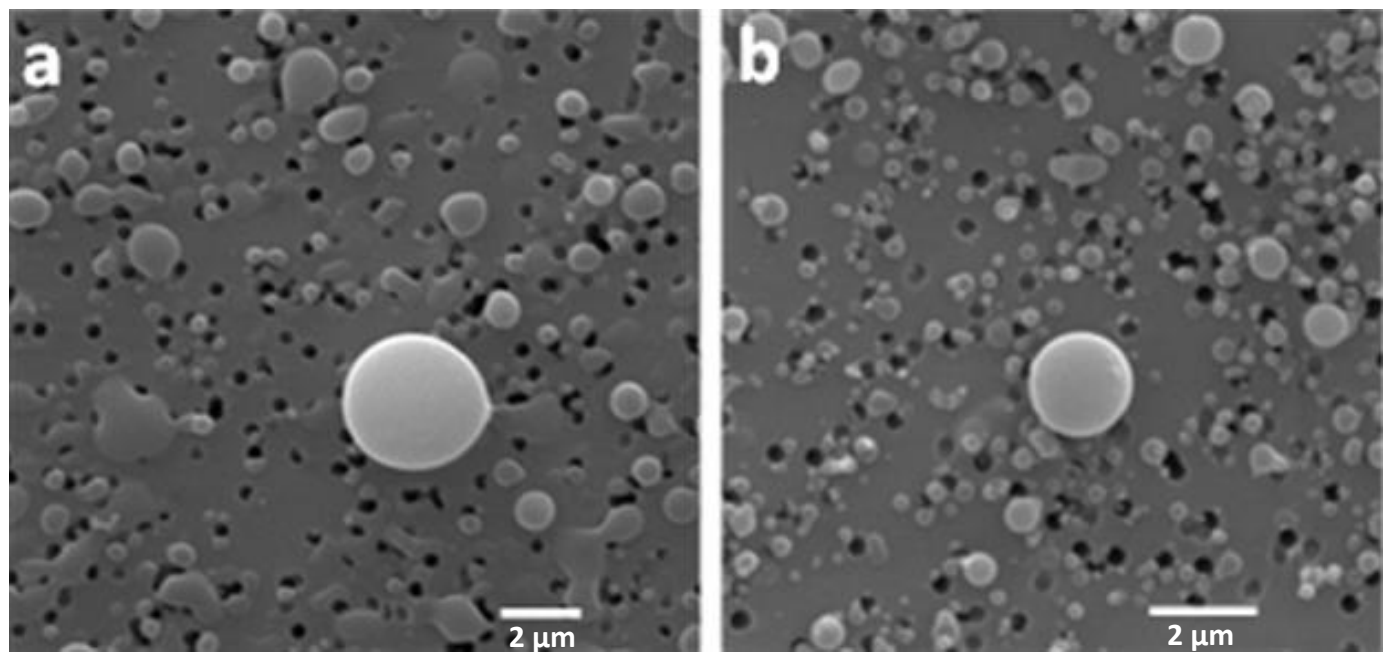

Figure 5. Diffusion accretion chains (soot particles) from top-lit updraft (TLUD) fires during pyrolysis stage I when the fire is establishing above the coal bed: (a) A high ventilation brazier; and (b) a low ventilation brazier.

\subsubsection{During the Pyrolysis Phase in a High Ventilation Brazier}

Figure 6 shows the micrographs of the particles formed during the flaming phase of BLUD and TLUD fires when using a high ventilation brazier. The results show that during the initial pyrolysis stage of the fire, spherical particles are formed in BLUD fires (Figure 6a), whereas conglomerate chained particles are evident in TLUD fires (Figure 6b). During late pyrolysis, giant conglomerates are formed from BLUD fires (Figure 6c), whereas in the TLUD fires, fine mode conglomerate particles are formed. 


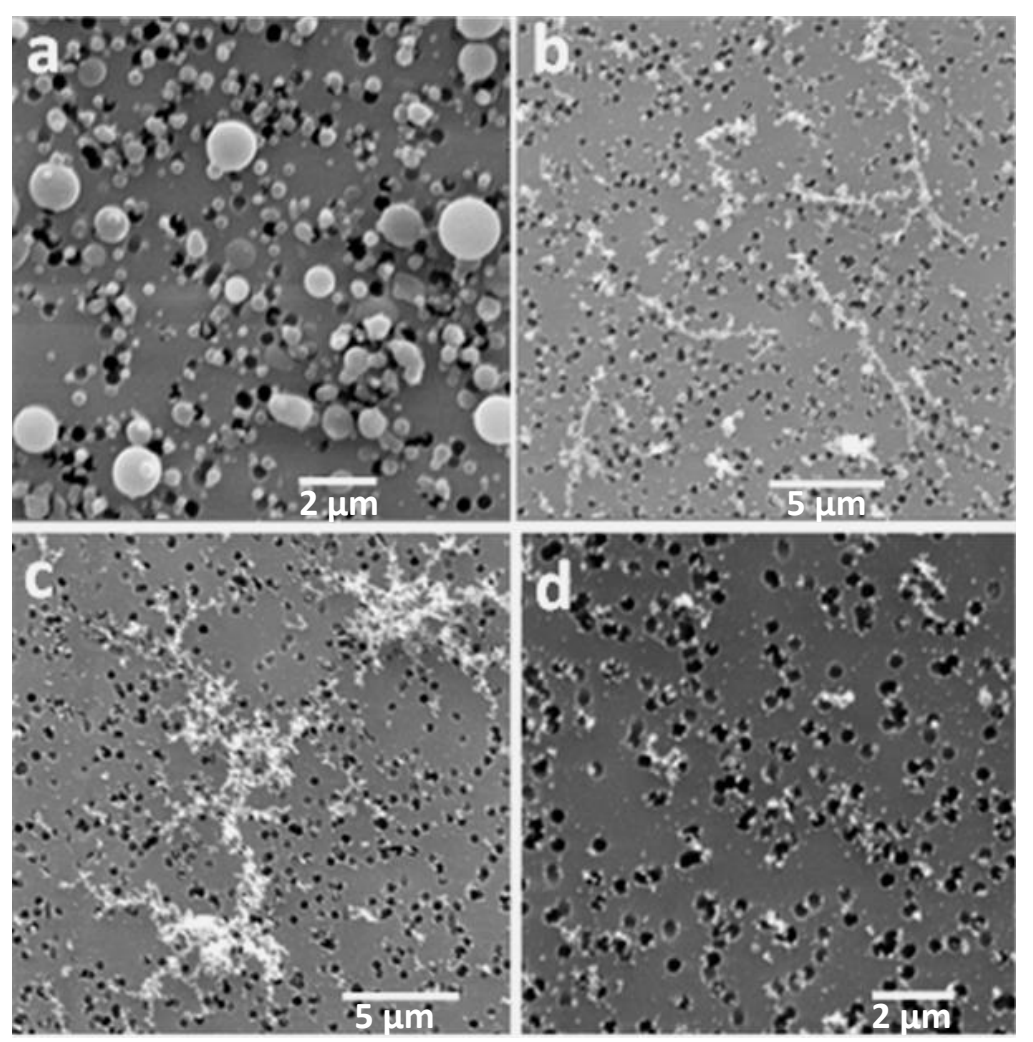

Figure 6. Ageing particles sampled from BLUD and TLUD fires; (a) Spherical organic particles from BLUD fires (early pyrolysis); (b) numerous condensation spherules and diffusion accretion chains from TLUD fires (early pyrolysis); (c) dendritic particles for BLUD during late pyrolysis; and (d) fine soot particles for TLUD during the char formation phase. Scale bars $=2 \mu \mathrm{m}(\mathbf{a}, \mathbf{d}) ; 5 \mu \mathrm{m}(\mathbf{b}, \mathbf{c})$.

\subsection{Identification of Diffusion Accretion Chains}

Figure 7 shows an electron micrograph with many diffusion accretion chains. These agglomerates have not been reported in previous studies on coal combustion, although there have been observed in experiments involving biomass burning smoke $[15-17,23,26]$. These diffusion accretion chains are formed from bimolecular homogeneous nucleation with water vapor, and they grow by coagulation and condensation. The low volatile organic compound (LVOC) released from the burning coal undergoes polymerization reactions with $\mathrm{OH}$ radicals in droplets, yielding larger molecular weight and less water-soluble species. Due to the Raoult's effect, the equilibrium size of the droplet is reduced. As the size of the droplet decreases, the solution becomes concentrated and the rate of polymerization increases, which results in turning the organic polymer largely insoluble in water. Spherical organic particles observed in this study are believed to remain as dry, low-vapor pressure solid particles.

Thujadeen et al. [28] contended that particle-particle collisions are the dominant particle growth mechanism, especially in the final stages of the flame synthesis process. The particles may restructure/rearrange following the collision, but they do not fully coalesce. This is because the diffusion-driven sintering timescales for viscous flow and grain boundary are slow relative to the timescale for collisions, even in high-temperature combustion conditions [28,29]. Consequently, flame synthesis generally leads to the production of aggregates/agglomerates (i.e., ensembles of point-contacting or overlapping near-spherical primary particles) $[28,30]$. 


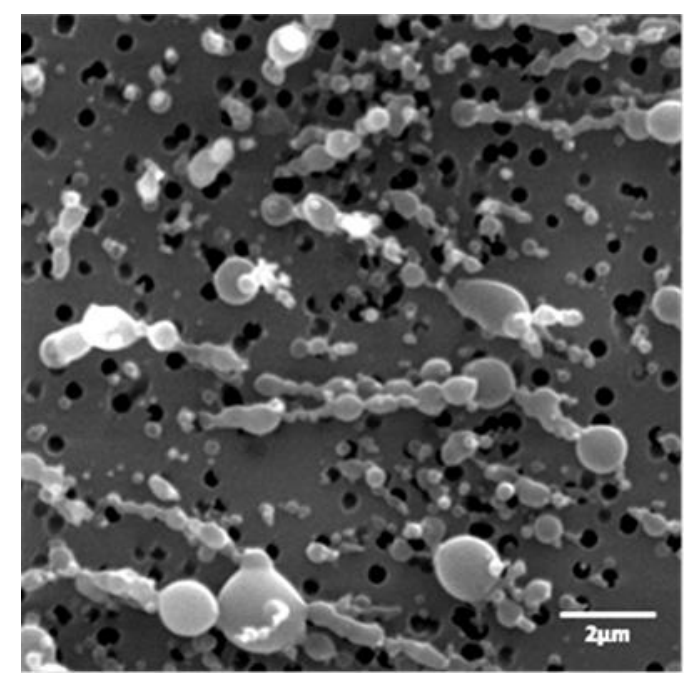

Figure 7. Micrograph showing numerous SOPs and diffusion accretion chains.

\subsection{Morphology of Spherical Organic Particles}

The morphologies of the sampled spherical organic particles from residential coal smoldering ignition conditions (typical of the BLUD method) are like atmospheric tar-ball particles [16,23,26] and polymeric organic compounds [27] reported in biomass smoke. These particles are presented as aggregates and individual particles.

From this study, it is evident that spherical organic particles occur in plumes of smoldering rather than of flaming fires. Martins et al. [31] noted that smoldering combustion produced more spherical particles than flaming combustion. Pósfai et al. [26] argued that tar-balls occur exclusively in biomass and biofuel combustion smoke since fossil fuel burning releases mostly apolar compounds that do not tend to polymerize under atmospheric conditions. They further argued that tar balls do not possess a semi-ordered microstructure or form aggregates. The authors then claimed that to their knowledge, individual particle studies of coal and oil burning emissions and of urban aerosols have not shown the presence of tar balls. However, this study has shown the presence of tar-ball-like spherical organic particles from coal combustion smoke particles, and has identified bead-like aggregates/diffusion accretion chains from spherical organic particles as they interacted with each other as shown in Figure 7.

\subsection{Mixing States in Spherical Organic Particles}

The spherical organic particles are found in three distinct states: (i) Bare-spherical organic particles without any inclusions (Figure 4); (ii) agglomerated-resulting in the formation of chains or aggregates (Figure 7); (iii) spherical organic particles with inclusions-the surface of the spherical organic particle has inclusions of fine mode particles. For example, Figure $8 \mathbf{b}$ shows a micrograph of observed spherical organic particles, with smaller spherical aggregates on the surface. These small aggregates may either originate from the direct condensation of vapor phase species or aggregation of nucleates formed from organic vapors [32]; and (iv) deformed particles-with structural defects, not uniformly smooth and spherical (Figure 9).

In this study, for the TLUD method, 50\% of the spherical particles analyzed were bare particles without any inclusions, 35\% were constituted of diffusion accretion chains, $10 \%$ had inclusions, and $5 \%$ were structurally deformed. For the BLUD method, it was noticed that bare spherical particles represented $65 \%$ of the spherical particles analyzed, with chain aggregates constituting approximately $25 \%$ and $7 \%$ for particles with inclusions, and structurally deformed spherical organic particles representing 3\%. The authors caution that the count of bare spherical particles might be under-estimated because some spherical particles had smaller diameters making it challenging to determine whether they had inclusions. As such, ultra-fine particles in the nanometer range diameters 
(i.e., below $500 \mathrm{~nm}$ ) were not included in this estimate. If the particle could not be easily distinguished, then the particle would not be classified in any of the groups.

Structural defects were observed in some of the near-spherical organic particles, as shown in Figure 9. Prolonged atmospheric processing of the spherical organic particles or ageing of the particles while fire emissions are drawn through the SEM filter ( 10 min) may explain the observed structural defects in some of the spherical organic particles. Similar results have been reported elsewhere $[17,23,26]$.
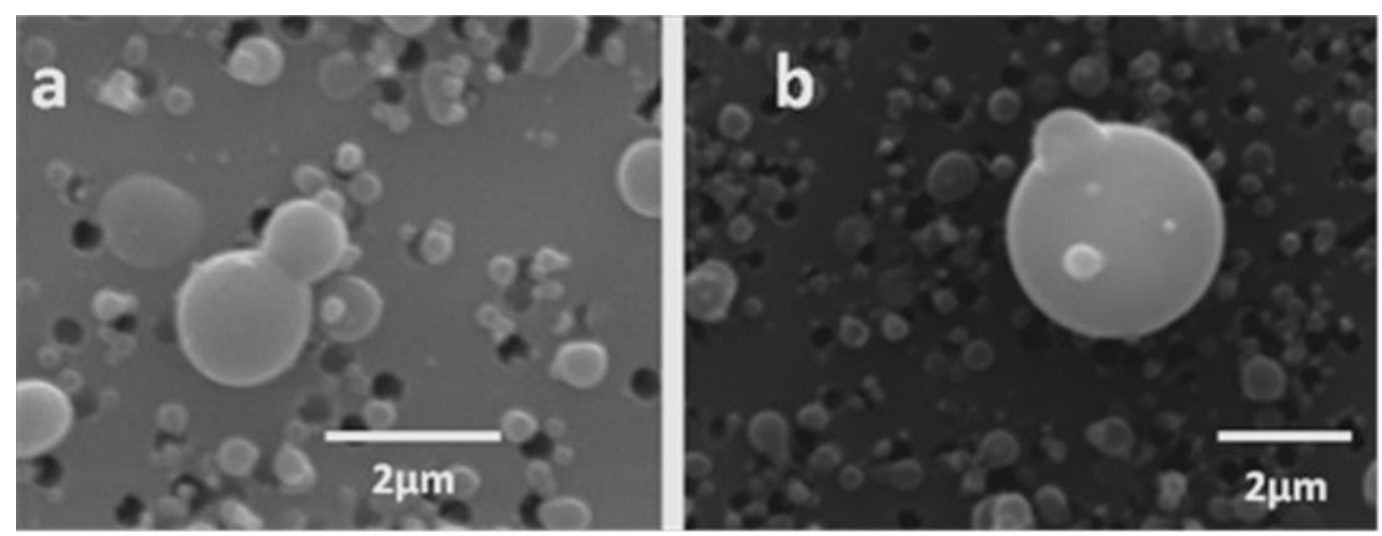

Figure 8. SEM micrographs showing mixed states of spherical organic particles: (a) Coalescing spherical organic particles; (b) spherical organic particles with surface inclusions.

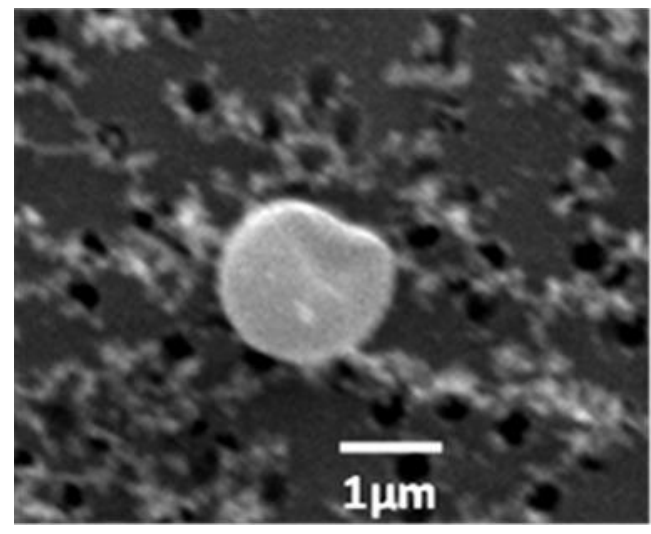

Figure 9. Spherical organic particle from the flaming phase of the BLUD fire showing a structural defect.

\subsection{Chemical Composition of the Spherical Organic Particles}

The majority of the identified spherical particles contained only $\mathrm{C}$ and $\mathrm{O}$, and other particles contained $\mathrm{C}$ and $\mathrm{O}$ plus other elements, such as $\mathrm{Si}, \mathrm{S}, \mathrm{Mo}, \mathrm{K}, \mathrm{Al}$ in trace amounts, which is consistent with previous observations of atmospheric tar-ball particles [23,26,33].

The average carbon-to-oxygen ratio of the spherical organic particles was calculated and determined to be $\sim 9$. The carbon background signal from the polycarbonate SEM filter substrate makes it difficult to decide on the exact carbon to oxygen ratio of particles. It is not possible to apply a correction factor for the background as it varies from particle to particle [17]. Our semi-quantitative EDX data show a higher average molar $\mathrm{C} / \mathrm{O}$ ratio (ranges from 8 to 10) in spherical organic particles from residential coal burning smoke, a difference that could result from the loss of O-rich functional groups (decarboxylation) in the vacuum of the electron microscope [26].

Similar to Tóth et al. [34] and based on the most characteristic features of the relatively fresh spherical organic particles (SOP) (i.e., spherical shape, large size, homogeneous composition, and high $\mathrm{C} / \mathrm{O}$ ratios), a direct emission mechanism is suggested for the spherules. The spherical particles indicate that the droplets do not only occur on the filter, but are already present in the exhaust or atmosphere 
where they formed a condensation process. These spherical particles are likely to be produced by the direct emission of liquid droplets followed by heat transformation upon coal burning. The authors hypothesize that the spherules are ejected from the pores of coal particles as liquid organic carbon droplets then undergo chemical changes that increase their viscosity, form aggregates, and solidify into highly refractory particles, as is generally observed in the atmosphere.

\subsection{Electronically Dark and Bright Spherical Particles}

By way of using secondary electron (SE) imaging of individual particles at a low accelerating voltage $(1 \mathrm{kV})$, two forms of spherical organic particles were identified and defined by China et al. [16] as electronically dark and bright. The spherical organic particles were classified into electronically dark and bright based on their grayscale intensity on the SE low accelerating voltages images. A semi-quantitative energy dispersive $\mathrm{X}$-ray analysis was conducted on 30 dark and 30 bright spherical organic particles of comparable size. The results showed that out of the 30 dark spherical organic particles, 24 showed higher average minor oxygen and carbon content than in bright spherical organic particles. The remaining six dark spherical organic particles showed similar oxygen content to the bright spherical organic particles, possibly due to the presence of an insulating layer or due to a somewhat subjective segregation of each spherical organic particle group [16]. It should be noted that these two forms of spherical organic particles could not be distinguished from each other at high accelerating voltages $(20 \mathrm{kV})$. It is contended that the enhanced contrast at low accelerating voltages is due to various degrees of oxidation states on the surface of the spherical particles. The darker spherical particles may be more oxidized and possibly have less volatile coating compared to bright spherical organic particles. China et al. [16] found these two forms of tar balls from smoldering conditions of biomass fires. Tivanski et al. [35] observed that tar balls from biomass combustion typically consist of $55 \%$ atomic carbon and $45 \%$ atomic oxygen, suggesting the presence of an oxygenated layer on the surface of the tarballs. Ivey [36] observed a similar SE contrast effect on zinc and zinc oxide samples.

This study further investigated if the backscattered electrons (BSE) could be used to distinguish between the two forms of spherical organic particles. There were no contrast differences between the two types. This result is similar to findings by China et al. [16] who argued that SEs are sensitive to the surface, whereas BSEs are sensitive to the bulk of the particle. Different contrasts in the SE images and similar contrasts in the BSE images highlight the fact that there could be an existence of a layer of varying composition at the surface of the spherical organic particles. This phenomenon needs to be investigated further.

\subsection{Implications for Health Risk and Environmental Impacts}

Spherical organic particles (SOPs), like many organic carbonaceous particles, are a significant source of absorption of solar radiation. SOPs are rich in brown carbon $(\mathrm{BrC})$, a light absorbing organic matter from soil humics, humic-like substances (HULIS), and tarry substances from smoldering combustion conditions [37]. Optical and thermal analyses [38,39], including electron microscopy techniques [40], have been used to provide evidence of the existence of some organic particles with light-absorbing properties [41]. Brown carbon absorbs strongly in the ultraviolet wavelength and less in the visible range [42]. $\mathrm{BrC}$ particles are generated from smoldering fires or solid fuel burning including veld fires and domestic cooking and heating processes [40]. According to Andrea and Gelenscer [37], the absorption efficiency and spectral dependency of $\mathrm{BrC}$ depend on the source of origin.

The absorption of solar radiation by $\mathrm{BrC}$ has a significant impact on the distribution of atmospheric energy and hydrologic processes [41]. Atmospheric $\mathrm{BrC}$ has the potential to intercept solar radiation before it reaches the surface thereby heating the atmosphere and in turn, cooling the surface. This impacts the formation of clouds through reduced evaporation and the suppression of cloud formation by an upward motion process [41]. According to Ramanathan and Carmichael [43], strong aerosol absorption may decrease mean evaporation and rainfall by impacting the radiative-convective coupling between the surface and the atmosphere. The severity of the impacts of atmospheric forcing 
induced by aerosols from anthropogenic sources has been documented elsewhere $[37,40,44,45]$ and is comparable to the forcing due to all greenhouse gases (GHGs) [41]. On a particle-to-particle basis, Alexander et al. [41] opined that spherical organic particles showed light absorption equal to or greater than that of soot particles, which are generally believed to be the dominant form of light absorbing carbon.

The health effects of combustion emissions depend on the size and physicochemical of the particles, and substances adsorbed onto the surface of the particles [46]. Smaller non-soot brown carbon particles with aerodynamic diameters of less than $2.5 \mu \mathrm{m}$ may induce negative health outcomes compared to larger particles $(>2.5 \mu \mathrm{m})$. The particles with aerodynamic diameters $>4 \mu \mathrm{m}$ are likely to be deposited in the mouth and throat during inhalation and can be filtered/ trapped by the nasal hairs. On the other hand, particles $\leq 2.5 \mu \mathrm{m}$ are of great importance from a health viewpoint, because of their high number density, ability to penetrate deep in the lungs, and enrichment in toxic constituents such as heavy metals, arsenic, mercury, polycyclic aromatic hydrocarbons (PAHs), silica, fluorides, black carbon (BC), and brown carbon $(\mathrm{BrC})$ [47]. The sizes of the particles emitted during domestic coal combustion processes are a function of combustion temperatures and the combustion phase. This phenomenon is the same for wood combustion $[46,48]$. The BrC particles may have other compounds, such as polyaromatic hydrocarbons (PAHs) sorbed onto their surface [46]. In instances where the BrC particles reach the alveolar region of the lungs, the PAHs are then absorbed into the bloodstream through alveolar epithelium cells. Fine and ultrafine $\mathrm{BrC}$ particles may also enter the extrapulmonary organs including the liver through trans-epithelial transport [46].

\subsection{Limitations of Research}

The arguments contained in this research are limited by the two variants of domestic coal-burning braziers used in some South African Townships, employing the bottom-lit updraft and the top-lit updraft ignition methods. Although particulate emissions from wood and other fuels, such as kerosene, are important for human health and climate reasons, they are not included in this paper. The experiments presented herein were all carried out in the laboratory. An inter-comparison of laboratory results with field tests is an important component of current international improved stove programs, but is not within the scope of this paper.

The variables in our systematic investigation included three parameters-the fire ignition method (BLUD versus TLUD); coal type (only a single coal grade type was used); and ventilation rates (high versus Low). Other important parameters, such as (a) fuel moisture content, (b) fuel size distribution and fuel load size, (c) stove diameter, and (d) grate height, were kept constant. A change in these parameters could result in different morphological characteristics of the particles emitted.

The optical properties and particle size distribution of the individual SOPs emitted during fixed-bed domestic coal-burning in a typical brazier were not monitored, as appropriate apparatus was not yet available in the laboratory. The evidence has pointed out that a large variation in emissions of light absorption particles results from different coal composition and burning conditions [20]. There is, therefore, a need in the future, to look at optical properties of SOPs from coal-brazier fires to curb uncertainties in radiative forcing predictions by transport models.

\section{Conclusions}

The images of filters sampled during the late pyrolysis phase and the char formation phase showed that the fire ignition method and ventilation rates influenced the formation of aerosols and the morphology of the emitted particles. The samples were collected close to the fire $(<1 \mathrm{~m})$ and at the exit of a $5 \mathrm{~m}$ chimney-estimated transit time $2 \mathrm{~s}$, to monitor the ageing of emitted particles. When sampling close to the fires (at ignition and early pyrolysis), the filter material rapidly clogged and a continuous layer of liquid/ tarry substance coalesced and covered the entire filter membrane, with some pores wholly closed. At the $5 \mathrm{~m}$ exit point, micrographs showed distinct particles morphologies, including large spherical organic particles that had condensed as the exhaust stream cooled. The perfectly 
spherical giant organic particles (SOP), very similar to atmospheric tar balls, were observed in ageing smoke from smoldering combustion conditions typical of poorly ventilated BLUD fires. The spherical organic particles were found as individual spherical particles and as aggregates forming diffusion accretion chains. Two distinct forms of spherical organic particles were observed, one less oxidized than the other. It is hypothesized that spherical organic particles may have been formed by the ejection of liquid tar droplets from the pores of the burning coal, followed by rapid thermal transformation upon passing through the flame or glow zone of the fire. The flame chemistry in the fire zone or multiphase chemical reactions in the smoke plume may contribute to the ageing of the ejected tar droplets forming accretion chains or aggregates. However, to understand better the complex processes of SOP formation in fixed bed coal combustion, further studies are necessary.

Author Contributions: T.M. conceptualized the research including carrying out the experimental work and analyzing the data. T.M. wrote the original draft of the manuscript and corrected the manuscript after comments from co-authors. J.M. was responsible for data curation, reviewing and editing the manuscript, supervision and funding acquisition. S.v.S. reviewed and edited the manuscript for scientific vigor and grammar.

Funding: This work was supported financially by the University of Johannesburg through a PDRF grant from the Faculty of Engineering and the Built Environment to TM, and in part from a grant from the Global Alliance for Clean Cookstoves (GACC) to the SeTAR Centre as a Regional Stove Testing and Development Centre. Part of the equipment and early stages of this work were funded by a grant from the South African National Energy Development Institute (SANEDI) for the project: ENV-0607-128 “Emissions testing from the BNM (Basa Njengo Magogo) reduced smoke fire lighting method". We thank the German GIZ, who provided substantial funding for the development of the SeTAR Laboratory through a legacy grant from the "Basic Energy and Climate Change Adaptation Programme" (BECCAP).

Acknowledgments: T.M. thanks Harold Annegarn for his guidance during the project. The authors would like to thank Daniel Masekameni and Thokozile Sithole for assistance with the combustion experiments. The authors also acknowledge the use of the SEM equipment at the University of Pretoria and the University of Johannesburg.

Conflicts of Interest: The authors declare no conflicts of interest.

\section{References}

1. Buseck, P.R.; Pósfai, M. Airborne minerals and related aerosol particles: Effects on climate and the environment. Proc. Natl. Acad. Sci. USA 1999, 96, 3372-3379. [CrossRef] [PubMed]

2. Burtscher, H. Sampling, measurement, and characterization of combustion aerosols for chemistry, morphology, and size distribution. In Aerosols from Biomass Combustion; Nussbaumer, T., Ed.; Bioenergy Task 32: Biomass Combustion and Co-firing; International Energy Agency (IEA): Zurich, Switzerland, 2001.

3. Li, H.; Xu, Q.; Zhang, D. Effects of mineral transformations on the reduction of PM2.5 during combustion of coal blends. Adv. Mater. Res. 2012, 356-360, 1306-1314. [CrossRef]

4. Silva, L.F.O.; Querol, X.; Da Boit, K.M.; de Vallejuelo, S.F.O.; Madariaga, J.M. Brazilian coal mining residues and sulphide oxidation by Fenton's reaction: An accelerated weathering procedure to evaluate possible environmental impact. J. Hazard. Mater. 2011, 186, 516-525. [CrossRef] [PubMed]

5. Silva, L.F.O.; Moreno, T.; Querol, X. An introductory TEM study of Fe-nanominerals within coal fly ash. Sci. Total Environ. 2009, 407, 4972-4974. [CrossRef] [PubMed]

6. Gwaze, P. Physical and Chemical Properties of Aerosol Particles in the Troposphere: An Approach from Microscopy Methods. Ph.D. Thesis, University of the Witwatersrand, Johannesburg, South Africa, 2007.

7. Fletcher, R.A.; Small, J.A.; Scott, J.H.J. Analysis of individual collected particles. In Aerosol Measurement, Principles, Techniques, and Applications; Baron, P.A., Willeke, W., Eds.; Wiley-Interscience: New York, NY, USA, 2001; pp. 295-363.

8. Silva, L.F.O.; Jasper, A.; Andrade, M.L.; Sampaio, C.H.; Dai, S.; Li, X.; Li, T.; Chen, W.; Wang, X.; Liu, H.; et al. Applied investigation on the interaction of hazardous elements binding on ultrafine and nanoparticles in Chinese anthracite-derived fly ash. Sci. Total Environ. 2012, 419, 250-264. [CrossRef] [PubMed]

9. Mhlaba, J.S.; Kearsley, E.P.; Kruger, R.A. Physical, chemical and mineralogical characterisation of hydraulically disposed fine ash from SASOL Synfuels. Fuel 2011, 90, 2491-2500. [CrossRef]

10. Lu, Y.; Rostam-Abadi, M.; Chang, R.; Richardson, C.; Paradis, J. Characteristics of fly ashes from full-scale coal-fired power plants and their relationship to mercury adsorption. Energy Fuels 2007, 21, 2112-2120. [CrossRef] 
11. Wentzel, M.; Annegarn, H.; Helas, G.; Weinbruch, S.; Balogh, A.G.; Sithole, J. Giant dendritic carbonaceous particles in Soweto aerosols. S. Afr. J. Sci. 1999, 95, 141-146.

12. Arora, P.; Jain, S. Morphological characteristics of particles emitted from combustion of different fuels in improved and traditional cookstoves. J. Aerosol Sci. 2015, 82, 13-23. [CrossRef]

13. Pöschl, U. Atmospheric aerosols: Composition, transformation, climate and health effects. Angew. Chem. Int. Ed. 2005, 44, 7520-7540. [CrossRef]

14. McDonald, R.; Biswas, P. A methodology to establish the morphology of ambient aerosols. J. Air Waste Manag. Assoc. 2004, 54, 1069-1078. [CrossRef] [PubMed]

15. Chakrabarty, R.K.; Beres, N.D.; Moosmüller, H.; China, S.; Mazzoleni, C.; Dubey, M.K.; Liu, L.; Mishchenko, M.I. Soot superaggregates from flaming wildfires and their direct radiative forcing. Sci. Rep. 2014, 4, 1-8. [CrossRef] [PubMed]

16. China, S.; Mazzoleni, C.; Gorkowski, K.; Aiken, A.C.; Dubey, M.K. Morphology and mixing state of individual freshly emitted wildfire carbonaceous particles. Nat. Commun. 2014, 4, 1-7. [CrossRef] [PubMed]

17. Chakrabarty, R.K.; Moosmüller, H.; Garro, M.A.; Arnott, W.P.; Walker, J.; Susott, R.A.; Babbitt, R.E.; Wold, C.E.; Lincoln, E.N.; Hao, W.M. Emissions from the laboratory combustion of wildland fuels: Particle morphology and size. J. Geophys. Res. 2006, 111. [CrossRef]

18. Makonese, T.; Masekameni, D.M.; Annegarn, H.J.; Forbes, P.B. Influence of fire-ignition methods and stove ventilation rates on gaseous and particle emissions from residential coal braziers. J. Energy S. Afr. 2015, 26, 16-28. [CrossRef]

19. Makonese, T.; Masekameni, D.M.; Annegarn, H.J.; Forbes, P.B. Emission factors of domestic coal-burning braziers. S. Afr. J. Sci. 2017, 113, 1-11. [CrossRef]

20. Bond, T.C.; Covert, D.C.; Kramlich, J.C.; Larson, T.V.; Charlson, R.J. Primary particle emissions from residential coal burning: Optical properties and size distributions. J. Geophys. Res. 2002, 107, 8347. [CrossRef]

21. Goldstein, J.I.; Newbury, D.E.; Echlin, P.; Joy, D.C.; Romig, A.D., Jr.; Lyman, C.E.; Fiori, C.; Lifshin, E. Scanning Electron Microscopy and X-Ray Microanalysis: A Text for Biologists, Material Scientists, and Geologists; Plenum Press: New York, NY, USA, 1992.

22. Kutchko, B.G.; Kim, A.G. Fly ash characterization by SEM-EDS. Fuel 2006, 85, 2537-2544. [CrossRef]

23. Pósfai, M.; Simonics, R.; Li, J.; Hobbs, P.V.; Buseck, P.R. Individual aerosol particles from biomass burning in southern Africa, 1, Compositions and size distributions of carbonaceous particles. J. Geophys. Res. Atmos. 2003, 108, 8483. [CrossRef]

24. Shi, Z.; Shao, L.; Jones, T.P.; Whittaker, A.G.; Lu, S.; Berube, K.A.; He, T.; Richards, R.J. Characterization of airborne individual particles collected in an urban area, a satellite city and a clean air area in Beijing, 2001. Atmos. Environ. 2003, 37, 4097-4108. [CrossRef]

25. Hand, J.L.; Malm, W.C.; Laskin, A.; Day, D.; Lee, T.B.; Wang, C.; Carrico, C.; Carrillo, J.; Cowin, J.P.; Collett, J.; et al. Optical, physical, and chemical properties of tar balls observed during the Yosemite Aerosol Characterization Study. J. Geophys. Res. Atmos. 2005, 110. [CrossRef]

26. Pósfai, M.; Gelencsér, A.; Simonics, R.; Arató, K.; Li, J.; Hobbs, P.V.; Buseck, P.R. Atmospheric tar balls: Particles from biomass and biofuel burning. J. Geophys. Res. Atmos. 2004, 109. [CrossRef]

27. Fu, H.; Zhang, M.; Li, W.; Chen, J.; Wang, L.; Quan, X.; Wang, W. Morphology, composition and mixing state of individual carbonaceous aerosol in urban Shanghai. Atmos. Chem. Phys. 2012, 12, 693-707. [CrossRef]

28. Thajudeen, T.; Jeon, S.; Hogan, C.J. The mobilities of flame synthesized aggregates/agglomerates in the transition regime. J. Aerosol Sci. 2015, 80, 45-57. [CrossRef]

29. Eggersdorfer, M.L.; Kadau, D.; Herrmann, H.J.; Pratsinis, S.E. Aggregate morphology evolution by sintering: Number and diameter of primary particles. J. Aerosol Sci. 2012, 46, 7-19. [CrossRef] [PubMed]

30. Eggersdorfer, M.L.; Pratsinis, S.E. Agglomerates and aggregates of nanoparticles made in the gas phase. Adv. Powder. Technol. 2014, 25, 71-90. [CrossRef]

31. Martins, J.V.; Hobbs, P.V.; Weiss, R.E.; Artaxo, P. Sphericity and morphology of smoke particles from biomass burning in Brazil. J. Geophys. Res. 1998, 103, 32051-32057. [CrossRef]

32. Wu, H.; Pedersen, A.G.; Glarborg, P.; Frandsen, F.J.; Dam-Johansen, K.; Sander, B. Formation of fine particles in co-combustion of coal and solid recovered fuel in a pulverized coal-fired power station. Proc. Combust. Inst. 2011, 33, 2845-2852. [CrossRef]

33. Adachi, K.; Buseck, P.R. Atmospheric tar balls from biomass burning in Mexico. J. Geophys. Res. Atmos. 2011, 116. [CrossRef] 
34. Tóth, A.; Hoffer, A.; Nyir"o-Kósa, I.; Pósfai, M.; Gelencsér, A. Atmospheric tar balls: Aged primary droplets from biomass burning? Atmos. Chem. Phys. 2014, 14, 6669-6675. [CrossRef]

35. Tivanski, A.V.; Hopkins, R.J.; Tyliszczak, T.; Gilles, M.K. Oxygenated interface on biomass burn tar balls determined by single particle scanning transmission X-ray microscopy. J. Phys. Chem. A 2007, 111, 5448-5458. [CrossRef]

36. Ivey, D.G. Microscopy: Science, Technology, Applications and Education; Mendez-Vilas, A., Diaz, J., Eds.; Formatex Research Center: Badajoz, Spain, 2010.

37. Andrea, M.O.; Galencsér, A. Black carbon or brown carbon? The nature of light-absorbing carbonaceous aerosols. Atmos. Chem. Phys. 2006, 6, 3131-3148. [CrossRef]

38. Bond, T.C.; Bergstrom, R.W. Light Absorption by Carbonaceous Particles: An Investigative Review. Aerosol Sci. Technol. 2006, 40, 27-67. [CrossRef]

39. Chen, Y.; Bond, T.C. Light absorption by organic carbon from wood combustion. Atmos. Chem. Phys. 2010, 10, 1773-1787. [CrossRef]

40. Alexander, D.T.L.; Crozier, P.A.; Anderson, J.R. Brown carbon spheres in East Asian outflow and their optical properties. Science 2008, 321, 833-835. [CrossRef]

41. Feng, Y.; Ramanathan, V.; Kotamarthi, V.R. Brown carbon: A significant atmospheric absorber of solar radiation? Atmos. Chem. Phys. 2013, 13, 8607-8621. [CrossRef]

42. Hoffer, A.; Gelencsér, A.; Guyon, P.; Kiss, G.; Schmid, O.; Frank, G.P.; Artaxo, P.; Andreae, M.O. Optical properties of humic-like substances (HULIS) in biomass-burning aerosols. Atmos. Chem. Phys. 2006, 6, 3563-3570. [CrossRef]

43. Ramanathan, V.; Carmichael, G. Global and regional climate changes due to black carbon. Nat. Geophys. 2008, 1, 221-227. [CrossRef]

44. Zhang, Y.; Shao, M.; Lin, Y.; Luan, S.; Mao, N.; Chen, W.; Wang, M. Emission inventory of carbonaceous pollutants from biomass burning in the Pearl River Delta Region, China. Atmos. Environ. 2013, 76, 189-199. [CrossRef]

45. Laskin, A.; Laskin, J.; Nizkorodov, S.A. Chemistry of atmospheric brown carbon. Chem. Rev. 2015, 115, 4335-4382. [CrossRef]

46. Shrestha, G.; Traina, S.; Swanston, C. Black carbon's properties and role in the environment: A comprehensive review. Sustainability 2010, 2, 294-320. [CrossRef]

47. Zhang, Y.; Schauer, J.J.; Zhang, Y.; Zeng, L.; Wei, Y.; Liu, Y.; Shao, M. Characteristics of particulate carbon emissions from real-world Chinese coal combustion. Environ. Sci. Technol. 2008, 42, 5068-5073. [CrossRef]

48. Kocbach, A.; Li, Y.; Yttri, K.E.; Cassee, F.R.; Schwarze, P.E.; Namork, E. Physicochemical characterisation of combustion particles from vehicle exhaust and residential wood smoke. Part. Fibre Toxicol. 2006, 3, 1. [CrossRef]

(C) 2019 by the authors. Licensee MDPI, Basel, Switzerland. This article is an open access article distributed under the terms and conditions of the Creative Commons Attribution (CC BY) license (http://creativecommons.org/licenses/by/4.0/). 